\title{
Blogging Identities on Israel/Palestine: Public Intellectuals and Their Audiences
}

Mira Sucharov, Carleton University

Brent E. Sasley, University of Texas, Arlington

ABSTRACT Drawing on our research and blogging on Israel and the Israeli-Palestinian conflict, we make three claims about the role of scholar-bloggers in the social media age. First, as scholar-bloggers with some degree of ethno-national attachments related to our area of expertise, we contend that we are well positioned to issue the kinds of critiques that may resonate more deeply due to the very subjectivity that some perceive as a liability. Second, through the melding of scholarly arguments with popular writing forms, scholar-bloggers are uniquely poised to be at the forefront of public engagement and political literacy both with social media publics and with students. Third, the subjectivity hazard is an intrinsic part of any type of research and writing, whether that writing is aimed at a scholarly audience or any other, and should not be used as an argument against academic involvement in social media. Ultimately, subjectivities of both consumers and producers can evolve through these highly interactive media, a dynamic that deserves further examination.

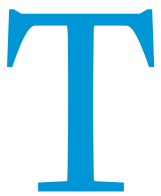
he explosion of social media in the last half decade has raised number of questions about the place of academics in the digital sphere, especially those engaged in the fields of politics and international affairs. For many active citizens, academics included, social media-including blogs, Twitter, and even Facebook-is now the default channel for consuming, discussing, and analyzing news and current events. Increasingly, scholars active in these arenas contend that they are an effective means of teaching, research, and dissemination of knowledge (Carpenter and Drezner 2010; Pressman 2012; Sides 2011). Similarly, surveys of the discipline indicate that academics are coming to believe that blogging should count toward tenure and promotion decisions alongside traditional publications (Long et al. 2012, 64, 69). ${ }^{1}$

Writing in $P S$ as a response to John Sides (2011), Robert Farley (2013) has reflected on the growing acceptance of blogging as legitimate political science. While he agrees that the discipline should provide "incentives" for faculty members who blog (e.g., tenure and promotion), Farley argues that trying to fold blogging too much into the discipline's existing structures runs the risk of imposing rigid conditions and qualifications on bloggers that

Mira Sucharov is associate professor of political science at Carleton University in Ottawa, Canada. She can be reached at mira.sucharov@carleton.ca.

Brent E. Sasley is associate professor of political science at the University of Texas at Arlington. He can be reached at bsasley@uta.edu. undermine the very benefits inherent in the nature of blogging (and, in our view, by extension tweeting, writing op-eds, and other social media engagement).

We share Farley's view. But including blogging and other social media activity as "legitimate" political science scholarship opens the door to another possible concern, which, while it is has always been present in more traditional publishing venues, may be intensified by these nontraditional activities: the intrusion of a scholar's own nonacademic identity (whether ethnic, religious, racial, gender, or simply ideological leanings) into the give-and-take that marks social media activity.

Whereas some people might argue that blogging and other social media engagement may challenge the roles and duties of academics (Tribble 2005), we contend that blogging and other types of social media activity paired with reflexive awareness of the kind of subjectivity that guides one's endeavors may actually enhance the scholarly and teaching enterprise. What's more, the traditional role of scholar-teacher as sage-on-a-stage may be well worth challenging. Drawing on the issue-areas that guide our own particular research and blogging agenda-Israel, Jewish affairs, and the Israeli-Palestinian conflict-we make three claims in this essay. First, as scholar-bloggers with some ethno-national attachments surrounding our area of expertise, we contend that we are well positioned to issue the kinds of critiques that may resonate more deeply within our communities because of our status as individuals with significant group attachments. This, despite the 
unpleasantness that sometimes results from taking aim at the dominant ideas and approaches that anchor one's ethno-national community. Second, through the melding of scholarly arguments with popular writing forms, scholar-bloggers are poised to be at the forefront of public engagement and political literacy both with social media publics and with our students. Third, the subjectivity hazard is an intrinsic part of any type of research and writing, whether the writing is aimed at a scholarly audience or others. Ultimately, being aware of the kinds of multiple audiences for whom we blog, and with whom we engage on social media, can help ensure that we are maximizing our potential to serve the public interest in all its manifestations, despite the contradictions and contestations that comprise the moral and political landscape of international affairs.

\section{FROM SCHOLARS TO SCHOLAR-BLOGGERS}

Despite what we might see as certain wedges of corporate or other control, the public sphere today is largely unmediated. Although those with authoritative voices do participate in the conversations, they do not always set-much less control-the agenda. On Twitter, for example, anyone can ask a public figure a question, and the response is also public, opening the door for anyone else to jump into the conversation. Individuals of all ranks, stations, question frequently melds into what we call a "why?!" question. This latter form of why?!-a statement of frustration, exasperation, and, frequently, moral outrage-is a redirected prescriptive question. But scholar-bloggers are well positioned to provide more strategic and normative context when we issue those statements of outrage. In turn, scholar-bloggers can potentially serve as a more thoughtful and constructive moral outlet for the kinds of frustrations that overtake concerned global citizens, as we step down out of the ivory tower and engage at the level of messyaround-the-edges human interaction.

The public nature of blogging and social media engagement also heightens the frequency and intensity of the criticisms one may face. Certainly, traditional academic writing is not immune to intellectual attacks. It is normally more polite, but not necessarily less biting. And whereas journals often will have specific sections dedicated to correspondence and debates between scholars, it is not unusual for some scholars to use another's work as a foil or counter-point to one's own argument without consulting the first writer (see Moravcsik 2010). But in the public sphere the form of public reckoning can be more disturbing and "unnatural" than scholars are used to. Both of us have faced harsh judgments and sometimes direct threats emanating from our public writingonce to the point of the president of one of our universities inter-

\section{In turn, scholar-bloggers can potentially serve as a more thoughtful and constructive moral outlet for the kinds of frustrations that overtake concerned global citizens, as we step down out of the ivory tower and engage at the level of messy-around-the-edges human interaction.}

and organizations interact through a uniform format with little regard for traditional hierarchical authority or knowledge (Shirky 2008). Although editors may exercise more control over comments and responses, the same process typically operates in blogs. As scholars, we are both on the receiving end and on the asking end of this real-time information exchange. In addition, new metrics of success are emerging alongside the traditional ones. While academia has generally used measures such as citation indexes within peer-review publications to calculate impact, social media users are more likely to look to numbers of Twitter followers as an indicator of the blogger-social-media-user's importance. Unlike the majority of authors who cite others' work, those followers tend to comprise both peer-professionals and those completely outside of one's field.

This flattening of certain hierarchies, the creation of new, crosscutting ones, and the seeming acceleration of time pose various challenges for social-media-engaged scholars. Some have noted the concern "that the relative ease of access may lead to superficial and ephemeral forms of engagement with issues that really require sustained dialogue and action on the ground" (Adams Parham 2005, 349-50; also Ong 2003). This observation is captured in the realization that, as social-media active social scientists, we sometimes slip into the type of reactive discourse common on the web. But this need not be considered entirely a drawback. Specifically, a common formulation of the task of social science has been to engage in four major lines of questioning: description, explanation, prediction, and prescription. But on social media and blogs, the kind of analytically detached "why" vening, and the federal authorities being called to investigate. In a gentler but still chiding fashion, both of us have been called to task by the self-named "Huffington Post Monitor," an upstart blog aimed at rooting out "anti-Israel bias" in articles appearing in the Huffington Post. These kinds of interventions force us to conduct what are normally elongated scholarly conversations in a much more immediate and compressed way. This requirement can make it more difficult to lay out a case or argument. At the same time, the public nature of these debates can close down genuine and serious dialogue. Often, the tone and tenor of the debate on Israel has descended to the level of judging the motives or emotions of the writer rather than evaluating the merits of the argument.

\section{IMAGINED AUDIENCES}

Thinking about the moral and political implications of how and why scholars conduct research is certainly not a new imperative (Burke 2008). In the specific case of the Israeli-Palestinian conflict, there is a long-standing debate over historiography and the role that scholars play in promoting particular narratives over others for ideological purposes (Silberstein 2008). In the stillcoalescing landscape of electronic social media and its blurring of the boundaries between "objective" scholarship and "subjective" identity, these questions deserve more attention.

The tension between the value of scholarly objectivity and the reality of a scholar's subjectivity is nothing new. Even bracketing the kind of ascriptive identities such as race, religion, and ethnicity that can be quite brittle, most scholars see themselves as part 
of a particular theoretical and methodological community. The common assumption that nonscholarly identity, which requires the promotion of a very subjective understanding of an issue under study (Hollenbaugh 2010; McCullagh 2008), conflicts with the roles of scholar and teacher, both of which require as much objectivity as possible to meet the standards of the profession, is a false dichotomy. In none of these arenas are scholars unbiased, and different identities come into play at different times.

Because scholarly careers can hinge on the prominence of particular paradigms or the popularity of certain methodologies, there is always the risk that certain data may be privileged or overlooked due to the demands of maintaining the appearance of intellectual consistency. The scholarly effects of experiencing oneself as belonging to a particular scholarly community are increasingly being investigated (see Bilgin 2008; Epstein 2011; Hallward 2010). Beyond the confines of disciplinary pressures, autoethnographic scholars in political science and international relations have brought the question of personal subjectivity more recently to the fore (Inayatullah 2011; Löwenheim 2010). These scholars suggest ways in which attention to one's personal experiences and vantage point can enrich observation and insight.

The potential problem of filtering one's ideas through the prism of an imagined audience-where one may tailor a message to bring about a desired reaction in the listener-becomes more relevant when blogging and engaging in social media. The brevity and speed of arguing through blogs and Twitter boils away the studied detachment suggested by traditional academic work, while the snark, egalitarianism, and intensity inherent in the staccatolike arguments of nontraditional outlets often brings out one's
As scholars, we naturally seek to engage the broader scholarly community. Both of us work in international relations and the areas of Middle East studies, Canadian and American foreign policy, and Diaspora Jewish politics. Between us, we also draw on other disciplinary concepts and approaches (e.g., sociology, psychology, psychoanalysis, cultural studies, linguistics), making our scholarly community potentially very large. We want to be as objective as possible because credibility among our colleagues is the central currency of the profession. That said, blogging lends itself to opinion writing as much as detached analysis, and here readers may interpret some of our offerings (although our respective styles often differ markedly from one another) as sometimes wading into the territory of actual politics rather than strictly political science.

At the same time, pedagogical opportunities need to be mined from the tension between the supposed ideal of scholarly objectivity and the reality of subjective preferences stemming from us being individuals with political opinions, beliefs, and judgments. As educators, our role is to foster critical thinking skills. Although we are careful to guide our students through an array of ideas, narratives, and interpretations (Caplan et al. 2012), between us we differ on the extent to which we choose to reveal our own ethnic, religious, or other subjectivity markers and policy preferences in the classroom. Nevertheless, through the subscriberbutton option, our students can follow us on Twitter, can access some of our Facebook content, and certainly can read our blogssome of which we assign. So they may quickly discover the contours of our identities as Jews and liberal Zionists with particular political leanings.

\section{Indeed, we often take a critical stand because we feel invested in the community. Implicating ourselves in the community also insulates our opinions from being perceived as outsider arguments, allowing us to demonstrate genuine personal concern for the community's health and future.}

nonacademic identities. The technicalities of the medium require arguments and claims to be shorter and more concise, and their immediacy sometimes forces writers to forego the careful, longview style inherent in much of the academic enterprise.

A second feature of social media is the nature of the audience, whereby the writer/poster contends with multiple potential audiences at any given moment of "exhibition" (Hogan 2010). Forcing the "presentation of self" (Goffman 1959) to be managed in a networked fashion provides a cautionary tale, but one infused with possibility. Imagined audiences are central to the highly networked world of digital interaction (Marwick and boyd 2011; Gruzd, Wellman, and Takhteyev 2011). In our own case-as two Jewish, North American scholars, self-described liberal Zionists ${ }^{2}$ studying the Israeli-Palestinian conflict, who favor a two-state solution and oppose the occupation, and who each maintain a personal Facebook page, a Twitter account, and one or more blogs ${ }^{3}$-we carry a set of different, and sometimes contradictory, audiences to whom we imagine we are speaking in our range of blogging, social media, and traditional scholarly activity. These include fellow scholars, students, and, the focus of our attention here, our "ethnic" community.
As concerned members of the Jewish community, our third audience is our fellow Jews, and especially our fellow Zionists. Given that we are active in our local or national Jewish communities, write for Jewish publications (among others), correspond with Jewish community officials and activists, and write on Jewish and Israeli issues and themes, we are sensitive to this community's concerns. This does not stop us from frequently making arguments at odds with the perceived general communal position on a given issue. Indeed, we often take a critical stand because we feel invested in the community. Implicating ourselves in the community also insulates our opinions from being perceived as outsider arguments, allowing us to demonstrate genuine personal concern for the community's health and future. We are aware that, in seeking to persuade our own ethno-religious "ingroup," we sometimes appear to be more oppositional to a given set of Israeli policies than we might be in another forum. But we increasingly feel that to be a devoted member of the Jewish community should mean abandoning a "my country, right or wrong" attitude in favor of bringing a critical eye to bear on Israeli-Palestinian relations. That said, we do self-censor at times, for example changing language in a blog post, perhaps avoiding certain topics, and so on, 
to avoid overly negative reactions. No one enjoys being insulted and harassed.

Writing for one's own community-whether purposely, in specific community mediums, or keeping our fellow ethno-nationals in mind in general blogs and op-eds-opens one up to harsh criticism of betraying the community and its causes. For example, many of the institutions of the Jewish community in the United States and, especially, in Canada have become increasingly identified with hardline Israeli policies, are reticent about criticizing Israel publicly, and frequently downplay the human rights violations inherent in the occupation. At the same time, popular Jewish opinion, particularly in the United States, is more directly supportive of Israeli concessions to the Palestinians than much of the organized community (J Street 2011). Because we are not firebrand ideologues-we are not on the hard right, the radical left, or even the perfect center-we exhibit a political identity that we feel speaks to broad empathic concerns on multiple sides of the debate. Being invested in a community's future infuses us with a desire to see the community's health continue, and our expertise should be brought to bear to that end.

In our own case, our detailed knowledge of the history and politics of Israel and Israeli foreign policy often come into play when we blog, tweet, and write in other public media. Our understanding of the nature of conflict and the role of domestic politics and identity on policymaking is no weaker because we are members of the community on which we write. Using models and findings of international relations scholarship, marshaling the necessary evidence, and being familiar with the major players in Israel and abroad all allow us to bring an ethno-cultural awareness to the issues under investigation.

\section{CONCLUSION}

Scholars, teachers, and students have much to gain from the use of social media. As educators, exposing our students to blogging and the politically informed use of social media can model the kind of public engagement that instills the value of active citizenship. As well, the kind of short-form writing that blogging and Tweeting requires, and the professional and activist networks to which one is exposed, can expand our research networks, gain access to political actors who may be more inclined to be interviewed for a media piece than for an academic tome, and try out incipient ideas that may later give rise to more fulsome research projects (Farley 2013, 383).

Questions of identity and responsibility have received less attention in the emerging discussions on blogging and academia. Reflecting on our personal experiences as scholar-bloggers and users of social media raises several issues academics should think about as they engage with these new technologies. We need to pay greater attention to how our own ethno-national (or other) identifications, which we nurture and develop through networks in social media forums, affect our scholarship. These questions are amplified and made more urgent by the use of social media that simultaneously reaches multiple audiences.

At the same time, the condensed nature of engagement in this public sphere emphasizes "why?!" questions and subsequent answers, which can be stultifying for a scholar who wishes to engage in deeper, longer, and more evidence-based discussions. With short-form blogging being an activity that needs to be done frequently and regularly, it is tempting to focus on the more immediate needs of reacting and responding to current events and to other voices in the blogosphere rather than devote the kind of

\section{With short-form blogging being an activity that needs to be done frequently and regularly, it is tempting to focus on the more immediate needs of reacting and responding to current events and to other voices in the blogosphere rather than devote the kind of shut-the-blinds and delve-into-the-data posture required for traditional academic peer-review publishing, where timelessness rather than timeliness is valued.}

Although not all members of an audience will applaud our specific goals and strategies, our credibility as scholars will matter. Not to everyone-again, the egalitarianism inherent in blogging and tweeting allow for nonspecialists or those with ideological agendas to dispute our conclusions on the basis of far less than would be considered acceptable in an academic publication. But on the basis of our own experience with blogging and on Twitter, others do take our arguments seriously and implicitly acknowledge our identities as scholar-bloggers.

What is also often left out of the conversation on scholarbloggers is its inevitability. Parallel to the allure and steady advance of technology generally, more and more scholars, especially in political science and international relations, are blogging and trying to write for the broader public. Moreover, as Ezra Klein (2013) has noted, the openness of the Internet has prompted the unmediated provision of expert analysis, putting scholarly knowledge in demand. If this process is inevitable, and our identities are not disappearing, then it makes sense to account for the latter and use them for the greater good. shut-the-blinds and delve-into-the-data posture required for traditional academic peer-review publishing, where timelessness rather than timeliness is valued.

The immediacy of reactions to what we write, and the unconstrained ability of our readers to couch such responses in ad hominem attacks or similar invectives, needs to be considered as well. These responses dilute the ability to hold a serious conversation and might even shape scholars' identities in ways they did not intend or expect, and physical threats to one's well-being may arise. This is particularly so in sensitive and polarizing issueareas such as the Israeli-Palestinian conflict.

Audiences, in turn, are naturally subject to the mutualconstitution of identity formation, maintenance, and challenge. Engaging in social media as academics and studying the laboratory of public engagement and identity evolution that it has become poses an undeniably exciting opportunity. And being aware of oneself and one's identity-indeed, mining this selfconsciousness for all its scholarly possibilities-is an asset to be embraced rather than a hazard to be avoided. 


\section{ACKNOWLEDGMENTS}

This paper was first presented at the Association for Israel Studies annual convention in Haifa, Israel, June 25-27, 2013. We thank Yossi Shain and Shmuel Rosner for comments on that earlier draft. We are also grateful to Rob Farley for his keen and very useful comments, as well as helpful comments from an anonymous reviewer.

\section{NOTES}

1. While Garden (2012) lays out the various and evolving definitions of "blogs," here we mean mostly self-standing 70o-80o word columns, more resembling op-eds or newspaper columns, but on digital outlets where sharing and tweeting is the norm. And while we consider ourselves academic bloggers, we do not tend to blog as much about employment conditions or the nature of the academy as much as about the subjects that we, as political scientists, study.

2. By liberal Zionists, we mean a commitment to maintaining Israel as a Jewish state and as a democracy, which means an end to the occupation as well as righting whatever discrimination exists within Israel against non-Jewish citizens.

3. We launched our blogging endeavors with a joint piece in The Huffington Post a few years ago. Today, both of us blog regularly for The Daily Beast / Open Zion, Mira blogs at Haaretz, and Brent blogs at The Huffington Post, the Times of Israel and at an independent blog called Mideast Matrix. Mira also maintains a regular column in two local Jewish community newspapers in Canada, while Brent frequently publishes at other media sites, such as The National Interest.

\section{REFERE N C E S}

Adams Parham, Angel. 2005. "Internet, Place, and Public Sphere in Diaspora Communities." Diaspora 14 (2/3): 349-80.

Bilgin, Pinar. 2008. “Thinking Past 'Western' IR?” Third World Quarterly 29 (1): 5-12.

Burke, Anthony. 2008. "Postmodernism." In The Oxford Handbook: International Relations, eds. Christian Reus-Smit and Duncan Snidal, 359-77. Oxford: Oxford University Press.

Caplan, Neil, Wendy Pearlman, Brent Sasley, and Mira Sucharov. 2012. "History, Rationality, Narrative, Imagery: A Four-Way Conversation on Teaching the Arab-Israeli Conflict." Journal of Political Science Education 8 (3): 288-302.

Carpenter, Charli, and Daniel W. Drezner. 2010. "International Relations 2.o: The Implications of New Media for an Old Profession." International Studies Perspectives 11 (3): 255-72.

Epstein, Charlotte. 2011. "Who Speaks? Discourse, the Subject and the Study of Identity in International Politics." European Journal of International Relations 17 (2): $327-50$.

Farley, Robert. 2013. "Complicating the Political Scientist as Blogger." PS: Political Science and Politics 46 (2): $383-86$
Garden, Mary. 2012. "Defining Blog: A Fool's Errand or a Necessary Undertaking." Journalism 13 (4): 483-99.

Goffman, Erving. 1959. The Presentation of Self in Everyday Life. Garden City, NJ: Doubleday.

Gruzd, Anatoliy, Barry Wellman, and Yuri Takhteyev. 2011. "Imagining Twitter as an Imagined Community." American Behavioral Scientist 55 (10): 1294-318.

Hallward, Maia. 2010. "International Relations Scholarship, Academic Institutions and the Israeli-Palestinian Conflict." Cambridge Review of International Affairs 23 (2): 259-80.

Hogan, Bernie. 2010. "The Presentation of Self in the Age of Social Media: Distinguishing Performances and Exhibitions Online." Bulletin of Science, Technology $\mathcal{E}$ Society 30 (6): 377-86.

Hollenbaugh, Erin E. 2010. "Personal Journal Bloggers: Profiles of Disclosiveness." Computers in Human Behavior 26 (6): 1657-666.

Inayatullah, Naeem, ed. 2011. Autobiographical International Relations: I, IR. New York: Routledge.

J Street. 2011. "National Survey of American Jews." GBA Strategies. https://s3 .amazonaws.com/s3.jstreet.org/images/J_Street_July2011SurveyData.pdf

Klein, Ezra. 2013. "Revenge of the Sources.” Wonkblog, Washington Post, March 10. http://www.washingtonpost.com/blogs/wonkblog/wp/2013/o3/10/revenge -of-the-sources/

Long, James D., Daniel Maliniak, Susan Peterson, and Michael J. Tierney. 2012. "TRIP Around the World: Teaching, Research, and Policy Views of International Relations Faculty in 20 Countries." at: http://irtheoryandpractice .wm.edu/projects/trip/TRIP\%202011\%20RESULTS\%20US\%20RESPONDENTS .pdf

Löwenheim, Oded. 2010. "The 'I' in IR: An Autoethnographic Account." Review of International Studies 36 (4): 1023-45

Marwick, Alice, and danah boyd. 2011. "I Tweet Honestly, I Tweet Passionately: Twitter Users, Context, Collapse, and the Imagined Audience." New Media \& Society 13 (1): 114-33.

McCullagh, Karen. 2008. "Blogging: Self Presentation and Privacy." Information $\mathcal{E}$ Communications Technology Law 17 (1): 3-23.

Moravcsik, Andrew. 2010. "Wahn, Wahn, berall Wahn': A Reply to Jahn’s Critique of Liberal Internationalism." International Theory 2 (1): 113-39.

Ong, Aihwa. 2003. "Cyberpublics and Diaspora Politics among Transnational Chinese." Interventions 5 (1): 82-100.

Pressman, Jeremy. 2012. "Sharpening Research Questions on Twitter." The Monkey Cage (blog). http://themonkeycage.org/2012/12/22/sharpening -research-questions-on-twitter/

Shirky, Clay. 2008. Here Comes Everybody: The Power of Organizing without Organizations. New York: Penguin Press.

Sides, John. 2011. “The Political Scientist as Blogger.” PS: Political Science and Politics 44 (2): 267-71.

Silberstein, Laurence J., ed. 2008. Postzionism: A Reader. New Brunswick, NJ: Rutgers University Press.

Tribble, Ivan. 2005. "Bloggers Need Not Apply." Chronicle of Higher Education. http://chronicle.com/article/Bloggers-Need-Not-Apply/45022. 